$$
\begin{gathered}
\text { 염수환경에서 탄소섬유/에폭시 복합재료의 } \\
\text { 내구성에 미치는 나노입자의 영향 }
\end{gathered}
$$

김부안 ${ }^{*}$ 문창권 ${ }^{*}$

*부경대학교 재료공학과

\title{
Nanoparticle Effect on Durability of Carbon fiber/ Epoxy Composites in Saline Water Environment
}

\author{
Bu-Ahn Kim ${ }^{*}$ and Chang-Kwon Moon ${ }^{*}$ \\ *Department of Materials Engineering, Pukyong National University, Busan, Korea
}

KEY WORDS: Nanopaticle 나노입자, Epoxy composites 에폭시계 복합재료, Saline water 염수, Durability 내구성

ABSTRACT: This study was conducted to investigate the durability of carbon fiber/epoxy composites (CFRP) in a saline water environment. The carbon fiber/epoxy composites were modified to use nanoparticles such as carbon nanotubes and titanum oxide. These hybrid composites were exposed to a saline water environment for a certain period. The weight gain according to the immersion time, a quasi-static tensile test, and micro-graphic characterization were used to investigate the samples exposed to the saline water environment. The weight gains increased with increasing immersion time. The weight gains of the hybrid composites were lower than that for pure CFRP throughout the entire immersion time. The tensile strengths decreased with increasing immersion time. The tensile strengths of the hybrid composites were higher than that of the pure CFRP throughout the entire immersion time. The pure CFRP was observed to be more degraded than the hybrid composites in the saline water environment. Therefore, it was concluded that the addition of nanoparticles to CFRP could lead to improved durability in a saline water environment.

\section{1. 서 론}

유리섬유 및 탄소섬유 등의 강화용 섬유와 수지 매트릭스를 조합시킨 복합재료를 일반적으로 섬유강화 고분자복합재료 (Fiber reinforced polymer composites)라고 포괄적으로 말하고 있다. 이들 재료는 탄성률과 강도가 높고, 밀도가 낮기 때문에 선박, 항공 및 우주항공과 같은 중량이 엄격히 제약을 받는 곳 에 적합한 재료로 인식되고 있다(Moon et al., 2005). 그리고 고 분자 나노복합재료(Polymer nanocomposites)는 유기 매트릭스 고분자와 나노미터의 충진재로 이루어진 복합재료를 의미하며, 이에 사용되는 충진재는 점토(Clay), 탄소 나노튜브(Carbon nanotubes, $\mathrm{CNT})$, 산화티타늄 $\left(\mathrm{TiO}_{2}\right)$ 분말 등 금속 또는 무기물 의 나노입자(Nanoparticles)들이 사용되고 있다. 첨가된 나노입 자는 매트릭스와 친화적인 경우에는 고분자의 가교밀도를 높이 고, 계면 결합력이 상승하는 한편, 균열 발생 시 진전속도를 늦 추는 효과를 가져다주기 때문에 복합재료의 기계적 물성을 향
상시킨다(Kim and Moon, 2013). 전보(Choi and Moon, 2013)에 서 탄소섬유강화 에폭시 복합재료에 $\mathrm{CNT}$ 와 $\mathrm{TiO}_{2}$ 분말의 나노 입자의 첨가가 실온과 고온의 증류수 환경에 대한 내구성에 어 떠한 영향을 미치는가에 대하여 평가를 행하였다.

따라서 본 연구에서는 탄소섬유강화 에폭시 복합재료에 CNT 와 $\mathrm{TiO}_{2}$ 분말의 나노입자의 첨가가 실온과 고온의 염수환경에 대한 내구성에 어떠한 영향을 미치는가를 평가하였으며, 기존 의 CFRP와 나노입자를 첨가시킨 하이브리드 복합재료의 내구 성을 비교 · 검토 하였다.

\section{2. 실 험}

\section{1 재 료}

본 실험에서 사용된 매트릭스 수지는 비스페놀-A형의 에폭시 수지가 사용되었고, 경화제로는 고온 경화재인 MNA(Methyl nadic anhydride), 경화 촉진제로 $\mathrm{BDMA}(\mathrm{Benzyl}$ dimethyl

Received 30 August 2013, revised 1 October 2013, accepted 13 February 2014

Corresponding author Chang-Kwon Moon: +82-051-629-6356, moonck@pknu.ac.kr

(c) 2014, Department of Materials Engineering, Pukyong National University

It is noted that this paper is revised edition based on proceedings of KSOE 2013 in Busan. 


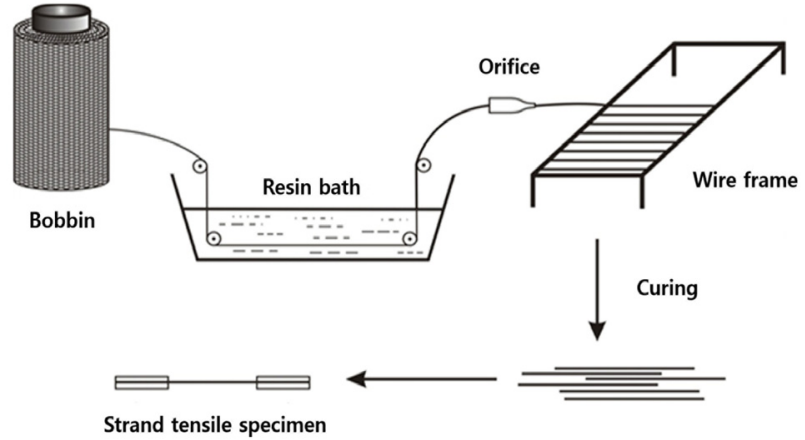

Fig. 1 Schematic of the process of the specimen

amine)가 사용되었다. 보강용 섬유로는 $12 \mathrm{k}$ 의 탄소섬유가 사용 되었으며, 충진재로 나노미터의 산화티타늄 $\left(\mathrm{TiO}_{2}\right)$ 분말 및 다중 벽 탄소나노튜브(Multi-wall carbon nanotube, MWCNT)가 사 용되었다. 염수환경은 증류수를 용매로 하여 염도 $5 \%(\mathrm{NaCl}$ $5 \%)$ 로 하였다.

\section{2 시험편 제작}

Fig. 1은 본 연구에서 사용한 스트란드 형(Strand type)의 시험 편을 제작하는 과정이다. 용매를 사용하여 점도를 떨어뜨린 에폭 시 수지 내에 나노입자를 첨가하여, 1 시간 동안 1000rpm으로 물 리교반을 시킨다. 이 후 초음파 분산기를 이용하여 1시간 동안 추가적으로 분산교반을 하였다. 나노입자가 혼합된 에폭시 수지 내에 보강섬유인 탄소섬유 다발을 Fig. 1과 같이 수지에 침지시 켜 특수 제작된 기구에 감아서 고정시켰다. 그 시험편을 $80^{\circ} \mathrm{C}$ 에 서 2 시간 동안 경화를 시킨 뒤, $140^{\circ} \mathrm{C}$ 에서 3 시간 동안 후 경화 열 처리를 통해 하이브리드 복합재료(Hybrid composites)의 시험편 을 제작하였다. 시험편 치수는 양쪽의 고정 탭의 길이는 각각 $50 \mathrm{~mm}$ 로 시험편 전체길이는 $180 \mathrm{~mm}$ 였다.

\section{3 무게 변화율 측정}

기존의 CFRP(Carbon fiber reinforced plastics)와 나노입자로 강 화시킨 하이브리드 복합재료 시험편을 염수환경에 침지시킨 후 일정침지시간에 따라 무게 변화율을 측정하였다. 무게 변화율 측정 은 실온과 고온 $\left(80^{\circ} \mathrm{C}\right)$ 에서 각각 시행하였다. 이 때, 무게 변화율은 표면의 수분을 제거한 후 $0.0001 \mathrm{~g}$ 의 정밀도를 가진 전자저울을 사용 하였으며, 다음 식 (1)을 이용하여 변화량을 측정하였다.

$$
\text { weight gain }(\%)=\frac{w_{i}-w_{o}}{w_{o}} \times 100(\%)
$$

상식에서 $W_{i}$ 는 수분환경에 침지 후의 시험편 무게이고, $W_{o}$ 는 수분환경에 침지 전 72 시간 $60^{\circ} \mathrm{C}$ 에서 건조시킨 시험편의 무 게를 나타낸다.

\section{4 인장 시험 및 파단면 관찰}

본 연구에서 각 시험편의 내구성 평가를 위해 인장시험을 시 행하였으며, $1.0 \mathrm{ton}$ 의 로드셀로 인장속도 $1.0 \mathrm{~mm} / \mathrm{min}$ 으로 인장 시험을 행하였다. 그리고 염수환경에서 침지시간에 따른 각 시 험편의 계면 열화정도를 알아보기 위해 침지 전·후 시험편의
Table 1 Volume fraction of fiber

\begin{tabular}{cccc}
\hline \hline & Fiber $(\mathrm{g})$ & Matrix $(\mathrm{g})$ & $V_{f}(\%)$ \\
\hline CFRP & 0.3357 & 0.1700 & 56.21 \\
CFRP + CNT & 0.2585 & 0.1300 & 56.38 \\
CFRP + $\mathrm{TiO}_{2}$ & 0.3223 & 0.1700 & 55.20 \\
\hline
\end{tabular}

인장시험 후의 파단면과 표면을 전자현미경(Scanning electron microscopy, SEM)을 이용하여 관찰하였다.

\section{5 섬유 체적함유율 측정}

Table 1은 연소법을 이용하여 측정한 CFRP의 탄소섬유 체적 함유율을 나타낸 것이다. 각 시험편 5 개를 사용하여 $350^{\circ} \mathrm{C}$ 전기 로에서 에폭시 수지만을 연소시켜 평균 섬유무게를 측정하여 섬유 함유율을 구하였다. 섬유체적 함유율 $\left(V_{f}\right)$ 은 Fig. 1에서 유 리 오리피스의 직경으로 조절을 하였으며, Table 1에서 알 수 있듯이 조금은 차이가 있어나 약 $56 \%$ 였다.

\section{3. 결과 및 고찰}

\section{1 무게 변화율}

Fig. 2는 실온과 고온에서의 염수환경에 일정시간 침지시킨 각 시험편의 무게변화율을 나타낸 것이다. 실온과 고온 모두 무 게 변화율은 침지시간이 20 일까지는 급격히 증가하다가 그 후 는 완만하게 증가하였으며, 침지시간이 길어질수록 무게 증가율

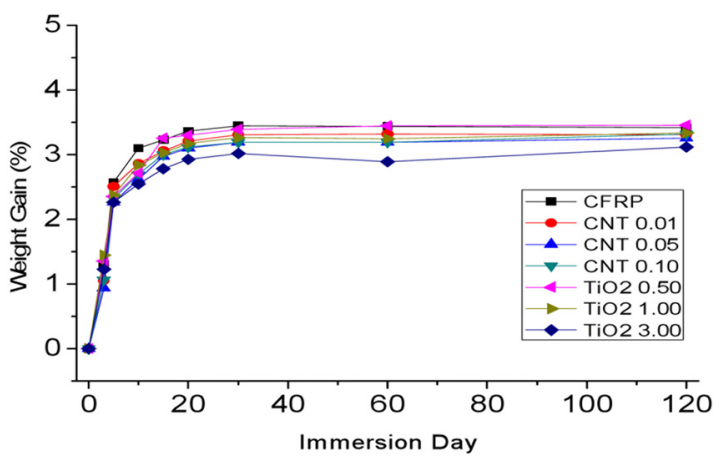

(a) Room temperature

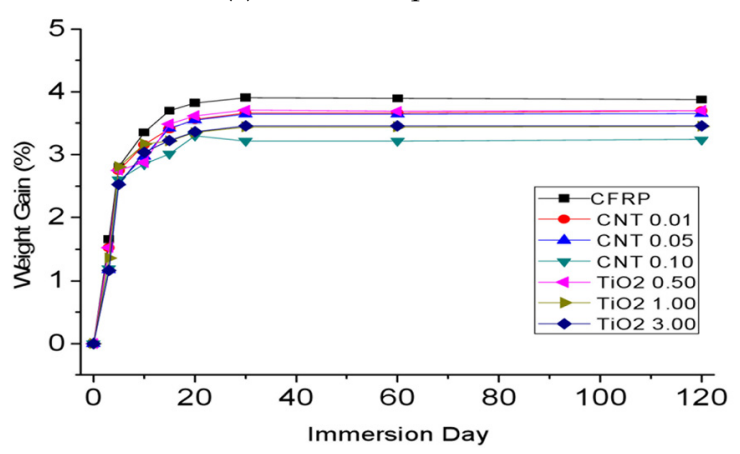

(b) $80^{\circ} \mathrm{C}$

Fig. 2 Weight gains of specimen according to immersion time in the saline water 
이 높았다. 특히, 실온과 고온 모두 전 침지시간에서 기존의 CFRP 시험편의 무게 변화율이 하이브리드 복합재 시험편에 비해 더 높았 다. 그리고 침지시간 전 구간에서 실온보다는 고온의 수분환경에서 의 무게 변화율이 더 높은 것으로 나타났다. 이것은 고온에서 실온 보다 더 활발한 분자운동에 의한 매트릭스 내 자유체적(Free volume)의 증가 때문에 매트릭스 수지내로 실온보다 수분침투가 용이함에 기인하는 것으로 생각된다(Choi and Moon, 2013).

\section{2 인장시험}

Fig. 3은 염수환경에 침지시키기 전 각 시험편의 인장 실험 결과를 나타낸 것이다. 모든 하이브리드 복합재의 시험편이 기 존의 CFRP에 비해 더 높은 인장강도 값을 나타내고 있다. 이것 은 나노입자의 첨가로 인한 Crack deflection 또는 Crack pinning 효과로 균열의 진전을 방해하는 효과뿐만 아니라 수지 자체의 물성 향상 및 섬유와 수지 간 계면에 작용을 하여 섬유 와 수지의 계면 결합력에 좋은 영향을 준 것으로 판단된다 (Bansal, et al., 2005; Dan et al., 2006 ). 그리고 하이브리드 복 합재 중에서 $\mathrm{CNT}$ 는 $0.05 \mathrm{wt} . \%$ 를 첨가한 것과 $\mathrm{TiO}_{2}$ 는 $3.00 \mathrm{wt} . \%$ 를 첨가한 것이 각각 가장 높은 인장강도 값을 나타내었다.

그러나 $\mathrm{CNT}$ 입자의 경우 $0.05 \mathrm{wt} . \%$ 초과 시 입자 간 응집 (Aggregation)으로 인하여 하이브리드 복합재료의 인장강도는 조금 감소한 것으로 보인다. 따라서 본 연구에서는 $\mathrm{CNT}$ 는 $0.05 \mathrm{wt} . \%$ 를 첨가한 것과 $\mathrm{TiO}_{2}$ 는 $3.00 \mathrm{wt} . \%$ 를 첨가한 하이브리드 복합재료를 표준 시험편으로 하여 염수환경에서 침지시험을 실 시하였다.

Fig. 4는 CNT/CFRP 시험편을 실온과 고온의 염수환경에 일 정시간 침지시킨 후 침지시간에 따른 인장강도를 나타낸 것이 다. 그림에서 전체적으로 수분환경에서 침지시간이 길어질수록 인장강도가 감소하는 경향으로 보이고 있으며, 실온 보다는 고 온에서의 감소폭이 더 큰 것으로 나타났다. 이것은 Fig. 2에서 전술한 바와 같이 침지시간이 길어질수록, 고온에서는 저온보 다 수분 흡수율이 높기 때문에 섬유와 수지 간 계면의 열화가 더욱 가속화된 결과라 판단된다.

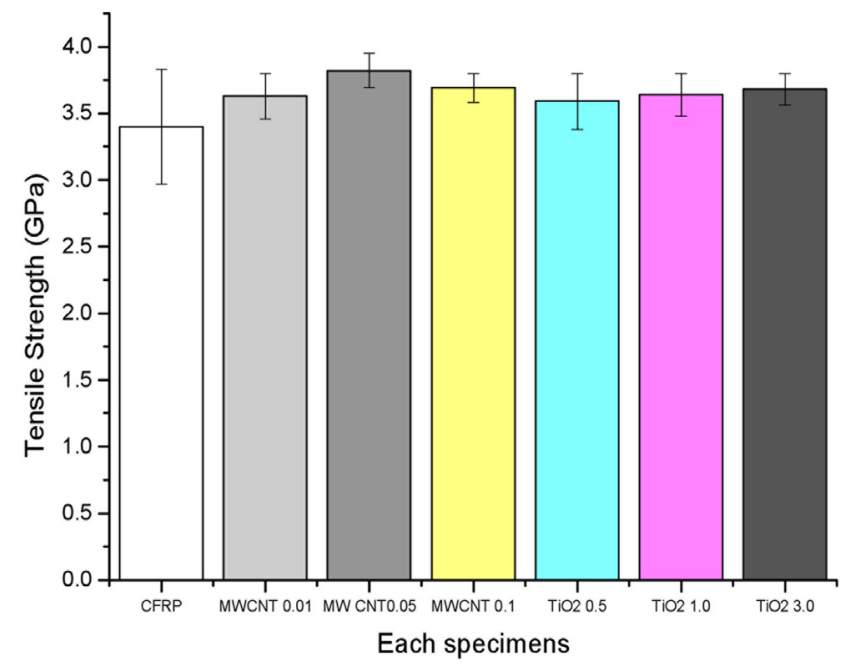

Fig. 3 Tensile strengths of the each specimen before immersion

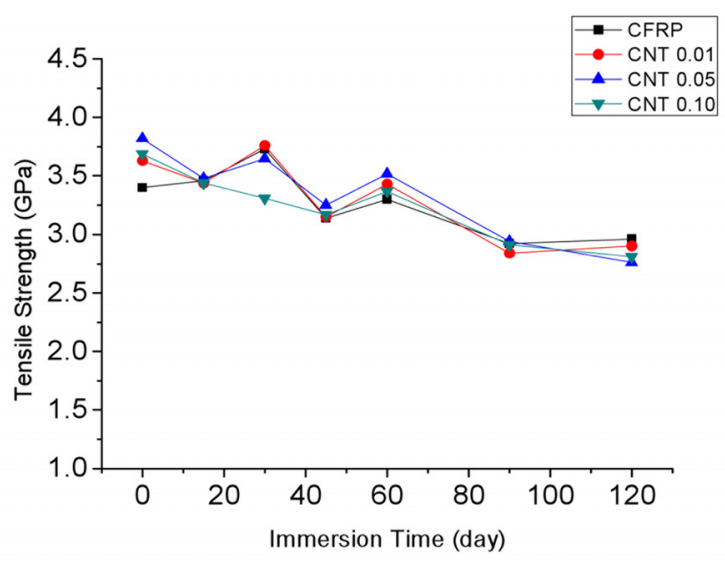

(a) Room temperature

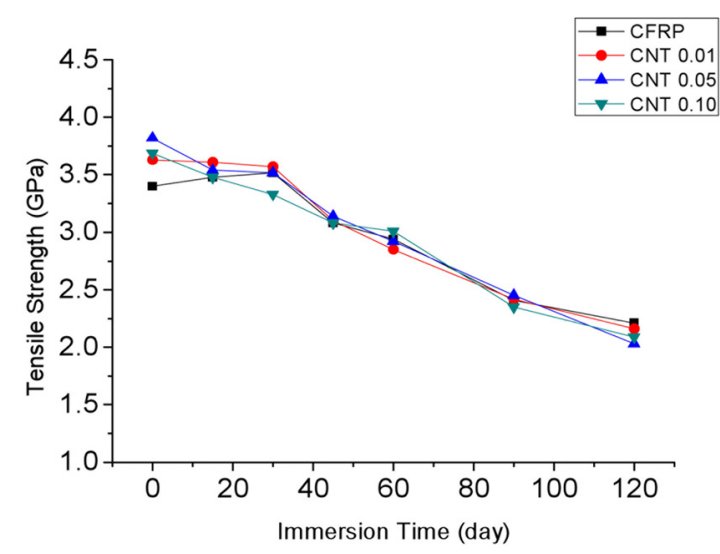

(b) $80^{\circ} \mathrm{C}$

Fig. 4 Tensile strength of CNT/CFRP composites as a function of the immersion time in the saline water

그리고 하이브리드 복합재료가 기존의 CFRP보다 인장강도가 전 침지구간에 있어서 크게 나타나 있는 것을 알 수 있다. 이것 으로 CFRP에 나노입자를 첨가함으로써 수분 흡수율을 저하시 키고, 이로 인해 섬유와 수지의 계면 결합력을 양호하게 유지시 켜 인장강도의 저하를 감소시키는 결과라 판단된다.

Fig. 5 는 $\mathrm{TiO}_{2} / \mathrm{CFRP}$ 시험편을 실온과 고온의 염수환경에 일 정시간 침지시킨 후 침지시간에 따른 인장강도 값을 나타낸 것 이다. 전체적으로 염수환경에서 침지시간이 길어질수록 인장강 도가 감소하는 경향으로 보이며, 실온 보다는 고온에서의 인장 강도의 감소폭이 더 큰 것으로 나타났다. 이것은 Fig. 4 에서와 거의 동일한 경향으로 나타났다. 하지만 침지시간의 전 구간에 있어서 $\mathrm{TiO}_{2} / \mathrm{CFRP}$ 복합재료의 인장강도는 CNT/CFRP 복합재 료보다 조금 적은 값을 나타내고 있다.

따라서 염수환경에 침지시킨 시험편은 침투된 수분으로 인한 매트릭스 수지 및 계면의 열화로 인하여 섬유와 섬유 간 하중 전달 매커니즘이 약화되었다. 결과적으로 복합재료의 인장강도 가 감소하는 것으로 판단된다.

\section{3 현미경 관찰}

현미경 관찰에는 $\mathrm{CNT}$ 는 $0.05 w t . \%$ 를, $\mathrm{TiO}_{2}$ 는 $3.00 \mathrm{wt} \%$ 를 첨 


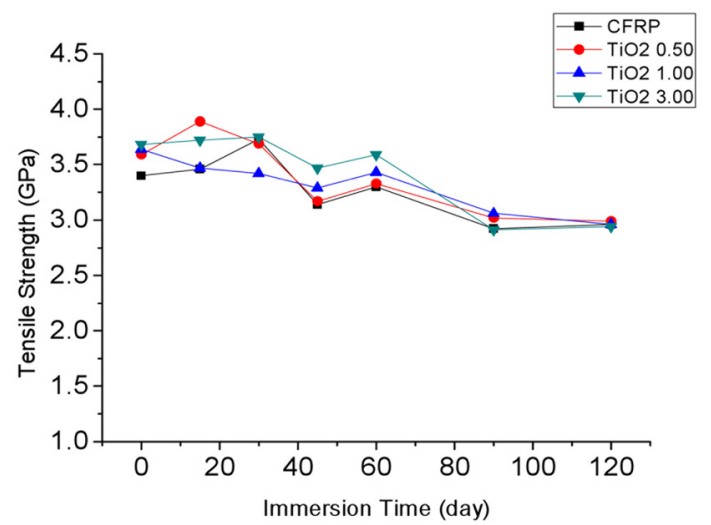

(a) Room temperature

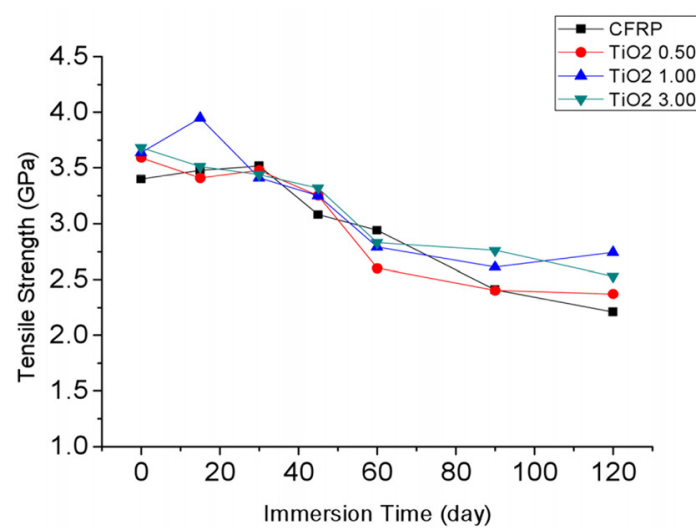

(b) $80^{\circ} \mathrm{C}$

Fig. 5 Tensile strength of $\mathrm{TiO}_{2} / \mathrm{CFRP}$ composites as a function of the immersion time in the saline water

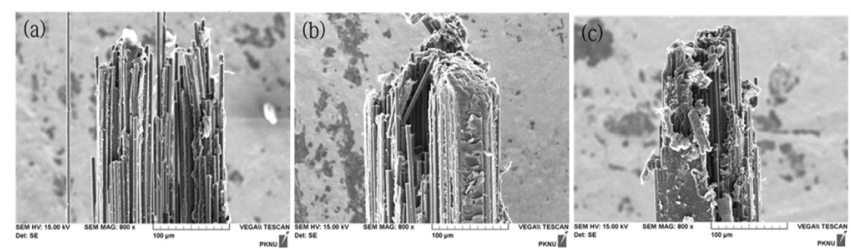

Fig. 6 SEM micrographs of the fracture surface of the strand type specimen (a) CFRP (b) CNT/CFRP (c) $\mathrm{TiO}_{2} / \mathrm{CFRP}$

가한 표준 시험편만을 사용하였다.

Fig. 6은 염수환경에 노출시키기 전 각 표준 시험편의 인장파 단 양상을 전자 현미경으로 관찰한 사진이다. 하이브리드 복합 재료에 비해 기존의 CFRP의 Pull-out 길이가 더 길게 나타났다. 또한 하이브리드 복합재료의 경우 섬유 주위로의 수지의 부착 상태가 기존의 CFRP에 비해 더 양호한 것으로 관찰되었다. 이 사진에서 정성적으로 나노입자를 첨가한 시험편이 수지와 섬유 의 계면결합이 기존의 CFRP에 비해서 우수하다는 것을 나타내 고 있다.

Fig. 7은 실온의 염수환경에 60일간 노출시킨 후 각 표준시험 편의 인장파단 양상을 전자현미경으로 관찰한 사진이다. 모든 시 험편에서 Pull-out된 영역이 전체적으로 나타난 것으로 수분환경

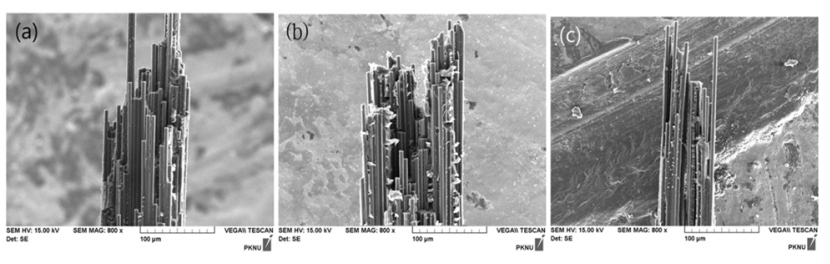

Fig. 7 SEM micrographs of the fracture surface of the strand type specimen after immersion of 60days in the saline water at room temperature (a) CFRP (b) CNT/CFRP (c) $\mathrm{TiO}_{2} /$ CFRP

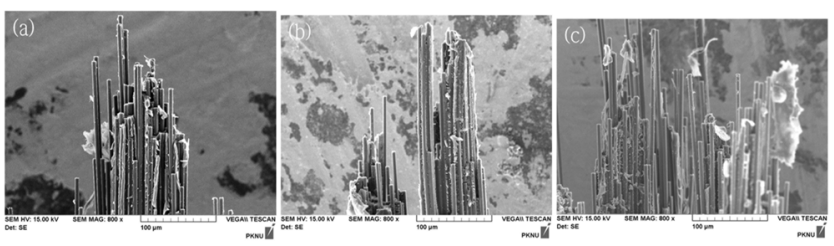

Fig. 8 SEM micrographs of the fracture surface of the strand type specimen after immersion of 60 days in the saline water at $80^{\circ} \mathrm{C}$ (a) CFRP (b) CNT/CFRP (c) $\mathrm{TiO}_{2} / \mathrm{CFRP}$

에 노출시키기 전보다 섬유와 수지 간 계면결합력이 비교적 열화 된 것을 알 수 있다. 그리고 나노입자를 첨가시킨 시험편 기존의 CFRP시험편에 비해 Pull-out된 섬유길이로부터 정성적으로 고 찰해보면 계면결합력이 보다 우수하다는 것을 알 수 있다.

Fig. 8 은 고온의 염수환경에 60 일간 노출시킨 각 시험편의 인 장파단 양상을 전자현미경으로 관찰한 사진이다. Fig. 7의 실온 과 비교하여 다소 체적팽창이 야기된 모습을 보인다. 특히, 기 존의 CFRP의 경우 Pull-out된 부분이 현저하게 나타났다. 이것 은 전술한 바, 고온의 경우 실온보다 수분침투가 용이하여 섬유 와 수지간의 계면이 더욱 열화된 결과로 판단된다(Moon et al., 2008; Prolongo et al., 2012).

Fig. 9는 고온의 염수환경에 120 일 동안 침지시킨 각 시험편
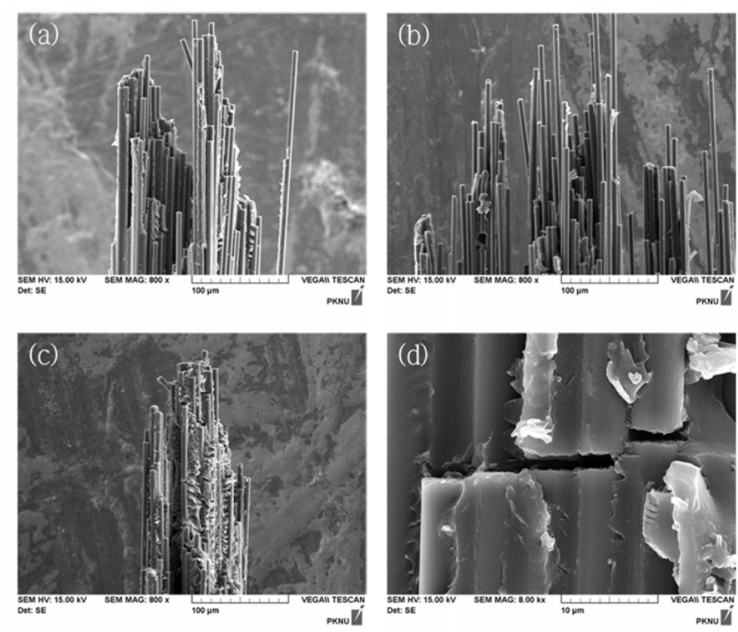

Fig. 9 SEM micrographs of tensile fracture surface of the specimen after 120days in saline water at $80^{\circ} \mathrm{C}$ (a) CFRP (b) CNT/CFRP (c) $\mathrm{TiO}_{2} / \mathrm{CFRP}$ (d) micro crack 
의 인장파단 양상을 전자현미경으로 관찰한 사진이다. 모든 시 험편에서 Pull-out 부분이 전체적으로 나타났으며, 기존의 CFRP 는 매끈한 섬유표면을 가지고 있으며, 나노입자를 첨가시킨 하 이브리드 복합재료는 섬유주위에 수지의 부착상태가 양호한 것 으로 나타났다. 이것은 인장 파단 시 저항의 흔적이 보이며, 나 노입자의 영향으로 섬유와 수진 간 계면결합강도가 개선되었다 고 판단된다(Musika et al., 2012; Kim et al., 2011; Rana et al., 2011). 그리고 Fig. 9(d)는 (c)의 일부를 미소영역으로 확대시킨 것이며, 섬유에 수지가 잔재한 채 끊어진 부분인 미소균열이 국 부적으로 관찰되었다. 이는 전술한 바, 염수환경에서는 수산화 이온 $(\mathrm{OH}-)$ 과 더불어 염소 이온 $(\mathrm{Cl}-)$ 이온으로 인한 재료의 화학 적 역학적 변화로 섬유와 수지 간 계면에 영향을 준 것으로 보 인다. 따라서 외부 응력에 의해서 생긴 Crack이 매트릭스 영역 에서 충분히 완충작용을 하지 못하고 섬유로 이어진 상태로, 염 수환경에서 매트릭스 자체의 열화에 의한 것이라고 판단된다.

\section{4. 결 론}

탄소섬유강화 에폭시수지 복합재료에 MWCNT 및 TiO2의 나노입자를 첨가하여 염수환경에서 내구성 향상에 대한 나노입 자의 영향을 비교·검토한 결과, 다음과 같다.

(1) 무게변화율은 모든 시험편이 염수환경에 노출된 시간이 길수록 무게가 증가하였다. 그 중에서도 기존의 CFRP가 나노입 자를 첨가한 하이브리드 복합재료에 비해 더욱 높았다.

(2) 인장강도는 모든 염수환경에서 침지시간에 따라 감소하는 경향으로 보였다. 이는 섬유와 수지간의 계면의 손상이 원인으 로 생각된다. 그리고 나노입자를 첨가한 하이브리드 복합재료 는 기존의 CFRP에 비해 다소 완만하게 감소하였다.

(3) 파단면 관찰 결과 염수환경에 침지된 시간이 길어질수록 섬유의 박리(debonding)가 크게 나타났다. 하지만 나노입자를 첨가한 하이브리드 복합재료는 기존의 CFRP에 비해서 양호한 계면 결합상태를 유지한다는 것을 알 수 있었다.

(4) 인장강도 및 계면을 관찰한 결과, 염수환경에서 전 침지구 간에서 기존의 CFRP에 비해 나노입자를 첨가한 하이브리드 복 합재료의 향상된 내구성을 관찰할 수 있었다.

\section{References}

Bansal, A., Yang, H., Li, C., Cho, K., Brian, B.C., Kumar, S.K., Schadler, L.S., 2005. Quantitative Equivalence Between Polymer Nanocomposites and Thin Polymer Films. Nature Materials, 693-698.

Choi, Y.M., Moon, C.K., 2013. Study of Nanoparticle Effect on Durability of Carbon Fiber/Epoxy Composites in Moisture Environment. Journal of Korean Society Power System Engineering, submitted.

Dan, C., Jacob, K., Tannenbaum, R., 2006. Characterization of Polymer Nanocomposites Interphase and Its Impact on Mechanical Properties. Macromolecules, 6565-6573.

Kim, B.A., Moon, C.K., 2013. Study on the Mechanical and Thermal Properties of $\mathrm{TiO}_{2} /$ Epoxy Resin Nanocomposites. International Journal of Ocean System Engineering, 3(2), 102-110.

Kim, M.T., Rhee, K.Y., Lee, J.H., Hui, D., Lau, Alan K.T., 2011. Property Enhancement of a Carbon Fiber/Epoxy Composite by Using Carbon Nanotubes. Composites: Part B, 1257-1261.

Moon, C.K., Takaku, A., 2005. Polymer Matrix Composites. Sigma Press, 2-12.

Moon, Y.J., Park, C.H., Moon, C.K., 2008. Study of the Durability of GFRP Composites in Alkaline Environment. Pukyong National University, Busan, Korea.

Musika, F., Vargas, G., Ibarretxe, J., 2012. Influence of the Modification with MWCNT on the Interlaminar Fracture Properties of Long Carbon Fiber Composites. Composites: Part B, 1336-1340.

Prolongo, S.G., Gude, M.R., Urena, A., 2012. Water Uptake of Epoxy Composites Reinforced with Carbon Nanofillers. Composites: part A, 2169-2175.

Rana, S., Alagirusamy, R., Joshi, M., 2011. Development of Carbon Nanofibre Incorporated Three Phase Carbon/Epoxy Composites with Enhanced Mechanical and Thermal Properties. Composites: Part A, 439-445. 